WellBeing International

WBI Studies Repository

9-2009

\title{
The SCHER Report on Non-human Primate Research - Biased and Deeply Flawed
}

\author{
Jarrod Bailey \\ British Union for the Abolition of Vivisection \\ Katy Taylor \\ British Union for the Abolition of Vivisection
}

Follow this and additional works at: https://www.wellbeingintlstudiesrepository.org/acwp_arte

Part of the Animal Experimentation and Research Commons, Animal Studies Commons, and the Design of Experiments and Sample Surveys Commons

\section{Recommended Citation}

Bailey, J., \& Taylor, K. (2009). The SCHER report on non-human primate research-biased and deeply flawed. Altern Lab Anim, 37, 427-435.

This material is brought to you for free and open access by WellBeing International. It has been accepted for inclusion by an authorized administrator of the WBI Studies Repository. For more information, please contact wbisr-info@wellbeingintl.org.

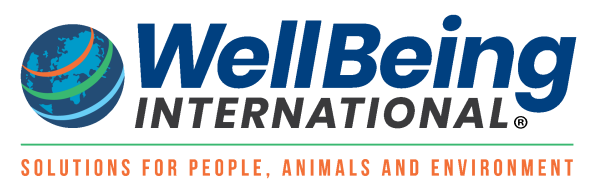




\title{
Comment
}

\section{The SCHER Report on Non-human Primate Research - Biased and Deeply Flawed}

\author{
Jarrod Bailey and Katy Taylor \\ British Union for the Abolition of Vivisection, London, UK
}

\begin{abstract}
Summary - The European Commission's Scientific Committee on Health and Environmental Risks (SCHER) recently issued an Opinion on the need for non-human primate (NHP) use in biomedical research, and the possibilities of replacing NHP use with alternatives, as part of the Directive 86/609/EEC revision process. Here, we summarise our recent complaint to the European Ombudsman about SCHER's Opinion and the entire consultation process. It is our opinion that the Working Group almost entirely failed to address its remit, and that the Group was unbalanced and contained insufficient expertise. The Opinion presumed the validity of NHP research with inadequate supporting evidence, and ignored substantial evidence against the need for NHP research and examples of valid alternatives that could replace the use of NHPs. Because the European Commission and others might base their approach to NHP research directly on the inquiry's findings during the revision of Directive 86/609/EEC, the implications of a flawed analysis of the efficacy of NHP research are extremely serious, both for animal welfare and for human health and safety. The conduct of the SCHER inquiry, and its published Opinion, should therefore be of major and widespread concern, and should not be given any political, scientific or legislative credibility.
\end{abstract}

Key words: alternatives, non-human primates, SCHER.

Address for correspondence: J. Bailey, British Union for the Abolition of Vivisection, 16a Crane Grove, London N7 8NN, UK.

E-mail: jarrod.bailey@mac.com

\section{Introduction}

European Union (EU) Directive 86/609/EEC, intended to ensure the protection of animals used in scientific research and testing, is currently undergoing a much-needed revision, more than 20 years after its adoption (1).

Of particular concern to many stakeholders is the fact that experiments which use non-human primates (NHPs), which have become especially controversial in recent years, are not afforded any specific attention under the current EU legislation. Polls consistently show that a majority of the British population oppose invasive and/or paincausing procedures on NHPs, whatever the proposed benefit to humans $(2,3)$ - an opinion that is reflected across Europe, where, most recently, 81\% of the public were reported to agree that experiments causing pain or suffering to NHPs should be banned (4). In 2007, the European Parliament adopted a declaration that urged an end to experimentation on great apes and wild-caught monkeys, and a commitment to phasing out NHP research altogether, after the declaration was supported by a majority of the MEPs (5).
In May 2008, building on this public and political concern, the European Commission (EC) mandated the Scientific Committee on Health and Environmental Risks (SCHER) to issue an Opinion on the need for non-human primates in biomedical research, and the possibilities of replacing NHP use with alternatives, as part of the Directive 86/609/ $E E C$ revision process. Following the submission of written evidence from stakeholders, followed by a meeting of interested parties at which the draft Opinion was discussed, the SCHER's final Opinion was published and adopted in January 2009 (6).

However, it is a widely-shared view that the final report produced by the Committee is far from the 'balanced, independent and scientific' opinion it was purported (as well as expected and required) to be. There are serious deficiencies in three key areas of the report and in how it was produced. In our view:

1. The Working Group (WG) did not adequately address the remit requested.

2. The balance of individuals within the working group was heavily skewed toward those individuals with expertise in animal-based research, with 
a serious absence of expertise in either specifically NHP research or the use of alternatives to NHP research.

3. The Opinion document itself is seriously flawed, because:

a) It presumes that non-human primate (NHP) research is scientifically valid, relevant to, and predictive for, humans. This default position of validity is held with no supporting evidence other than anecdote, rhetoric and opinion, with a lack of systematic and comprehensive evidence borne of comprehensive, robust and critical scientific evaluation. Crucially, in our opinion, before any assessment of the validity, scientific performance and human relevance of alternatives can be made, the imperative first step must be to ascertain the validity, scientific performance and human relevance of the NHP models currently being used in research and testing, that those alternatives are intended to replace.

b) It contains very little of the substantial amount of evidence against the requirement for NHPs in research that was provided by animal-protection stakeholders, and is therefore unbalanced. Even if the Committee disagreed with this evidence, it should have been included and rebutted.

c) It clearly seeks reasons to support the use of NHPs, and reasons against adopting alternatives. Due to the inescapable and high ethical cost of using NHPs in research and testing, the onus should instead have been on the Committee to do the opposite, namely, to explore reasons for not using NHPs and to actively encourage the use of alternatives.

In this commentary, we present our views on the SCHER Opinion. We outline the basis of the above objections, present examples of the many unsubstantiated statements made by the SCHER in its Opinion in support of NHP research, and provide examples of serious omissions of alternative methods and evidence against NHP research that were supplied to the Committee. We believe the entire process was unsound from its inception to its completion, and that the resulting Opinion document should not be given any political, scientific or legislative credibility.

\section{Concerns Regarding the Remit}

The EC requested the SCHER to issue an Opinion on: current areas of NHP research; current possibilities for replacement; scientific timetable for a phase-out of NHP use; opportunities for the reduc- tion and refinement of their use in areas where no replacement can be foreseen in the medium term, i.e. areas deserving Three $\mathrm{Rs}_{\mathrm{s}}$ investment; and implications for biomedical research, should NHP use be banned in the EU. Demonstrably, the SCHER Opinion fails to consider all of these points with any degree of significance, with the exception of the first - areas in which NHP are currently used. While 14 of the 25 pages of text are devoted to this first topic, scant attention is given to the others and, most critically, the implications of a ban on NHP use are not addressed at all.

\section{Current possibilities for replacement}

The vast subject of alternatives to NHP research is tackled in just 3.5 pages of the Opinion, with the first half-page constituting a position statement in support of animal models. There is no evidence of a literature review regarding the status of alternative methods, nor of any consultation with the EC's own experts via the European Centre for the Validation of Alternative Methods (ECVAM).

\section{Consideration of the concept of 'replacement'}

Crucially, the WG has neither defined 'replacement', nor examined in any detail what is actually required of a replacement method. It clearly expects any alternative to wholly and directly substitute for the use of NHPs - an approach that is not only naïve, but is out of touch with how those that research and promote alternative methods view their purpose or utility.

A broader approach recognises that alternatives can allow scientific objectives to be met without direct 'like-for-like' replacement. For example, alternative strategies can increase the availability of human organs for transplantation, obviating the use of animal organs in xenotransplantation. This broader approach requires researchers to ask, "What information do I need to solve this problem?" rather than "How do I do what I want to do without using NHPs?" It is clear that the former question is more conducive to identifying methods that would avoid NHP use. Indeed, this approach is reflected in the wording of Directive 86/609/EEC itself, in Article 7(2): "An experiment shall not be performed if another scientifically satisfactory method of obtaining the result sought, not entailing the use of an animal, is reasonably and practicably available." (1).

This concept appears not to be recognised by the $\mathrm{WG}$, and this is reflected in its inadequate analysis of the current and future situation with regard to replacement. Actual opportunities for replacement are rapidly dismissed in the Opinion with no substantiation; for example, "The total replacement of 
animals, including NHPs in testing for safety, is not possible based on present knowledge" (p. 22).

\section{Examples of promising alternatives disregarded by the $W G$}

Many papers detailing work that can replace NHPs in a multitude of different fields were supplied to the Committee, but were disregarded. For example, in the SCHER Opinion:

\section{In the field of Safety Testing:}

a) Microdosing $(7,8)$ is misrepresented as a complete replacement (p. 22), and therefore its use in detailing the pharmacokinetic (PK) profile of a drug (replacing the use of NHPs for this role) is completely dismissed.

b) Similarly, the US National Academy of Sciences (NAS) report Toxicity Testing in the 21 st Century (9) is dismissed entirely, as this focused on chemicals rather than drugs. Although there are many key aspects within the report that can apply to pharmaceuticals, these were not investigated.

c) The use of in vitro human-based cell culture systems for ADME/Tox screening is barely mentioned, despite the fact that the Committee was provided with papers detailing the predictivity of such systems (e.g. 10-12), as well as on methods for further improving them (for example, by the use of three-dimensional cultures $[13,14]$ and microfluidic chips [15-17]).

d) Similarly, no mention is made of the promise of functional human tissue assays that measure physiological effects at the level of the organ, cell, or even the gene. Such approaches "are often superior to extrapolation from animal data" $(10,18)$ and could have detected the adverse reactions caused by Cox-2 inhibitor drugs such as Vioxx, which caused over 320,000 heart attacks and strokes, killing 140,000 people, despite the cardioprotective results obtained in pre-clinical NHP tests (e.g. 19).

e) Progress that has been made in constructing the human immune system is also not mentioned, e.g. the presence of a fully-human modular immune in vitro construct $\left(\mathrm{MIMIC}^{\circledR}\right)$ for the efficacy testing of potential vaccines, developed "in response to the recurrent failure of animal vaccine protection studies to accurately predict human trial results." It measures vaccine immunogenicity via induction of the memory B-cell response - traditionally an area of high demand for NHPs $(20,21)$.

\section{In the field of Infectious Disease Research:}

a) Culture systems for infectious hepatitis $\mathrm{C}$ virus (HCV) in vitro now exist, enabling human-specific research, but the extent to which this obviates the need to infect NHPs (22) is entirely overlooked in the Opinion ( $p$. 24).

b) Alternatives in malaria research are dismissed, because they may not mimic the entire 'whole body system', despite providing equivalent information. For example: imaging technologies which permit the visualisation of individual malarial parasite-derived molecules in living cells (23); human livercell cultures which permit the study of interactions between the human immune system and the malarial parasite (24); and genetic studies with human volunteers, which have identified a novel $P$. falciparum gene (MB2I), the product of which could be exploited as a vaccine target, and which have helped our understanding of how gene expression in the parasite influences parasitic survival and pathogenesis $(25,26)$.

c) Genetic screens that can replace NHPs for vaccine testing, but have inexplicably failed to be fully implemented, such as the MAPREC system for polio vaccine consistency batch testing $(27,28)$, are not even mentioned.

\section{In the field of Neuroscience Research:}

a) Alternatives to NHP use, such as humanbased studies, are barely discussed, despite the provision to the Committee of papers demonstrating that epidemiological studies, imaging techniques and the use of human post-mortem brain tissue have impacted greatly on our knowledge of causative factors, and our understanding of brain function and regeneration in Parkinson's Disease patients (29-31).

b) Similar papers related to the relative value of human-based research for stroke are also not discussed. Imaging techniques can monitor changes in the human brain following stroke and after treatment for the condition, and cultured human blood vessels and human brain slices are being used to study contributory factors to stroke, as well as repair mechanisms and treatments (32-34).

c) Papers demonstrating that comparison of brain activity or behaviour between healthy and impaired volunteers can give equivalent information to primate brain-damaging studies, such as hippocampus damage and memory impairment $(35,36)$, are also not considered. 
d) Similarly, the use of implanted eye coils (37) or eye tracking devices (38) in healthy human volunteers, obviating the need for non-invasive primate vision research, are disregarded.

e) Opportunities for replacement in neuroscience research, with imaging technologies such as Magnetic Resonance Imaging (MRI) and Functional Magnetic Resonance Imaging (fMRI), Positron Emission Tomography (PET), Transcranial Magnetic Stimulation (TMS), are dismissed in the Opinion with no substantiation or justification: “...fMRI studies cannot replace studies collected with invasive microelectrode techniques; these are much more precise anatomically and temporally" (p. 24).

f) The use of invasive single-cell recording techniques in humans undergoing surgery is briefly mentioned (p. 18), but not with reference to replacement. Single-neuron recordings have been used several times in conscious epileptic patients (e.g. 39), and another study demonstrated that neural responses to visual objects within the hippocampus proper are directly linked to visual memory performance (40). The fact that such studies are possible should seriously call into question the need, on a caseby-case basis, for invasive NHP research.

\section{In the field of Xenotransplanation Research:}

a) There is no discussion on obviating the need for xenotransplantation research by increasing the availability of human organs for donation and reducing the incidence of heart disease through dietary education.

b) Evidence was provided to suggest that a combination of approaches could obviate the need for animal organs: i) The instigation of an optout 'presumed consent' organ donor system has seen huge increases in organ donation and transplantation rates in countries which have adopted it $(41,42)$. A similar system of mandated choice has produced hundreds of thousands of new donors in Sweden, the impact of which is further amplified, because each donor can potentially provide several organs (43). In addition, the use of kidneys from 'living donors' has greatly increased transplant rates in the USA and Norway, for example (44); ii) Just under half of all heart transplants are for cardiomyopathy, some of which are preventable. Just under half again are for coronary heart disease, of which the vast majority (if not all) are preventable (45). Around 100,000 first-time heart attacks could be avoided each year in the USA alone, if peo- ple cut their intake of saturated fat by just $1-3 \%$ (46).

\section{A scientific timetable for a phase-out of NHP use}

This important section is discussed in just half a page of the Opinion, covering four research areas. No time-scale for replacement, in the short, medium or long term, is provided. Genuine efforts should have been made to evaluate the use of NHPs by subject area, and to provide such timescales, which could have been derived according to the current status of, and investment rates in, alternative methods.

\section{Opportunities for reduction and refinement in the meantime}

Reduction and refinement methods are arguably more researched and implemented than replacement methods. Nonetheless, this section of the Opinion is restricted to just two pages. Though a number of refinement and reduction opportunities are mentioned, little detail and discussion is provided, and in most cases, no reference is made to scientific papers.

\section{Areas of the Three Rs which deserve investment}

Given the conservative conclusions reached by the WG regarding the Three $\mathrm{R}_{\mathrm{s}}$ in NHP use, this section should have been much more extensive than the half-page of very broad recommendations for 'more research'. To be useful to policy makers and funding bodies, detailed and clear scientific and regulatory requirements should have been supplied, by research area, for the replacement of NHPs - as opposed to a brief list of generic suggestions such as, "Further research in the use of genetically altered animal models or other suitable mammalian species in testing of vaccines and pharmaceuticals."

\section{Implications of a ban on NHP use for biomedical research}

There is no specific section dealing with this crucial question. While the opinion of the WG on the implications for biomedical research may be inferred from their detailed coverage of the first issues considered (areas of NHP experimentation), this is no substitute for a thorough analysis of the implications, in real scientific, medical and financial terms, of an immediate ban (or even a phasedin ban) on NHP research. 
Such an analysis is imperative, specifically in terms of the number of research projects affected, any reduction in the production of drugs, and so on. All claims and caveats should be substantiated. A vital part of this would be to analyse the evidence for the utility and validity of NHP research, which the WG completely fails to address. Examples of research that would have provided information on the likely implications of a ban, but that were overlooked in the Opinion, are discussed below.

\section{Concerns Regarding the Working Group}

The balance of individuals within the working group was heavily skewed toward those with expertise in general animal based research, with a perturbing absence of expertise in NHP research and in the use of alternative methods. Nine of the 11 members were animal researchers, of which just five were experts in primate use - the focus of the SCHER Opinion. Neither of the SCHER committee members who were also members of the WG, were experts in NHP use, and only four of 11 members were experts in alternative methods. Just one was an expert specifically in the use of alternative methods to NHP use, though this expertise is in the refinement of animal experiments in general.

Alternatives for chemical toxicology were summarily dismissed (p. 23) as not being relevant to the use of NHPs, yet the Chair of the WG was an expert in this field. Absent from the WG were experts from ECVAM and other Three Rs institutes within the EU, such as the UK NC3Rs or the Netherlands Centre for Alternatives to Animal Use. Indeed, we are not aware that consultation with these expert bodies was sought, or whether specific comments were received from them. Also absent from the WG were external experts in alternatives such as neuroimaging and refinement, and other experts from many Three Rs organisations worldwide. Similarly, the make-up of its WG did not benefit from the European Commission's own partnership with industry in the form of the European Partnership for Alternative Approaches to Animal Testing (EPAA, which has the remit to help accelerate the development and acceptance of new Three $\mathrm{Rs}$ methods in regulatory toxicology).

\section{Omission of Crucial Evidence Against the Efficacy and Necessity of NHP Research}

In addition to the examples of disregarded alternatives to NHP research detailed above, further evidence that the SCHER Opinion is seriously flawed comprises: a) unsubstantiated statements made by the SCHER in support of NHP research; and b) substantial evidence against NHP experimentation that the SCHER overlooked. Salient examples of unsubstantiated statements from the Opinion (in italics), and relevant referenced evidence that was disregarded, include:

\section{In the field of Safety Testing:}

"NHPs may be more predictive for human toxicity [in reproductive toxicology]." (p. 13). No evidence whatsoever is provided in the Opinion, of the predictive nature of NHPs for human pharmacokinetics/pharmacodynamics/safety, or for the superiority of NHPs over non-primate species. On the contrary, there is ample evidence to the contrary, which was supplied to the SCHER.

For example: $34 \%$ of NHPs in regulatory safety tests are subjected to single-dose toxicity tests that have been discredited (47); an International Conference on Harmonisation (ICH) guideline admits that primate toxicology data "can differ from humans as much as other species" (48); NHP developmental toxicity data correlate with human data just $50 \%$ of the time, less even than results from more evolutionarilydistant species such as rats, hamsters and ferrets (49); there remains "no statisticallycredible evidence" that NHP toxicology data "contribute any predictive value, either separately or in combination" (for example, with dog data; 50); and, for the prediction of druginduced liver injury, NHPs are less predictive than rodents - which failed to predict up to $51 \%$ of effects in humans (51).

\section{In the field of Infectious Disease Research:}

"Several vaccines currently used to protect humans against fatal infectious diseases have been developed through studies in NHPs." ( $\mathrm{p}$. 15). Not only is this claim unsubstantiated, but also the WG confuses the use of NHPs with critical evidence of their necessity, validity and reliability as part of the vaccine development process. A great deal of evidence was provided to the WG, which illustrated critical species differences affecting vaccine research and development, and even outright failures of $\mathrm{NHP}$ models. HIV, hepatitis $\mathrm{C}$ and malaria were specifically mentioned.

Given that no effective AIDS vaccine exists, despite a quarter of a century of testing in NHPs, the claims of NHPs "playing a key role in AIDS vaccine development" (p. 15) are fallacious. Claims that SIV-infected macaques are an important tool, ignore the lack of correlation between pre-clinical and clinical data, as well as evidence outlining important differences between HIV-infected humans and SIV-infected 
macaques, including differences in virulence, virus genetics and biochemistry, and pathology (52-59) - as summarised by Bailey (60). Protective and/or therapeutic vaccine responses have been elicited in chimpanzees via many vaccination methods. Despite the fact that more than 85 different vaccines have been tested in around 200 clinical trials, protection and/or significant therapeutic effects have not been demonstrated by any vaccine to date in humans, despite decades of effort and extensive research funding (60).

Nor are there human vaccines for hepatitis $\mathrm{C}$ or malaria, despite years of intense NHP research. There are critical differences between HCV infection in chimpanzees and humans that are not noted in the Opinion, including different rates of chronic infection and viral clearance, and differences in pathology, such as the incidence of liver fibrosis, cirrhosis, and hepatocellular carcinoma, mother-to-infant transmission, and immune response (summarised in 61). Recently, the ability to culture infectious HCV in vitro has been achieved and improved, opening new doors for human-specific research (62).

Similar differences confound malaria research. Although chimpanzees are susceptible to the main human malaria parasite, $P$. falciparum, it causes only brief and moderate parasitisation and no severe infection, and other species differences in susceptibility to the parasite exist, due to receptor variability (63). There are also serious questions as to whether the New World monkey challenge model (NWMCM) is sufficiently relevant for humans, as it consists of an unnatural host, challenged by an unnatural route of administration of an unnatural inoculum, which can result in variable infection rates and little correlation with results in human trials (64).

\section{In the field of Neuroscience Research:}

"This knowledge [from basic neuroscience research in NHPs] is useful... to understand effects and consequences of brain and spinal cord damage in humans and to devise therapies.” (p. 17). NHPs differ from humans in the spatial arrangements of their spinal cord tracts, corticospinal termination patterns within the ventral horn differ between primates, and differences exist in the function of central pattern generators - an important area of concern when attempting to translate research results from NHPs to humans (65).

"Stroke research does not use large numbers of NHPs, but the importance of their availability as a research tool is significant." (p. 19). There are significant species-specific and even strainspecific differences in response to ischaemic injury (66). Greater than 1,000 putative stroke drug candidates have been tested in animals with no success in humans (67). NHPs have been widely used, and it has not been established that they are superior to non-primate species in terms of human relevance. Experts have concluded: "Ischaemic stroke is a case study in failed translation" (41), and "the stroke community needs to think long and hard about whether these animal models are financially and ethically viable." (68).

"Their use is considered essential in several research programs such as on immune based diseases (e.g. multiple sclerosis), neurodegenerative disorders (Parkinson's, Alzheimer's, etc), infectious diseases (HIV, Malaria, TB, Hepatitis, $S A R S$, etc.) and other serious diseases."(p. 6). Our original submissions of evidence to the SCHER contain detailed rebuttals of this claim and its association with all of these diseases. Some disease-specific information is discussed earlier in this commentary. Further examples include: a) an argument that animal models of Alzheimer's disease have been a failure, due to significant confounding species differences, with very little progress made in understanding the various pathologies associated with the disease (69); and b) evidence that schizophrenia has not been reproduced experimentally in NHPs, nor have preventive measures, diagnostic tools or treatments been developed through them (70).

\section{In the field of Xenotransplanation Research:}

"However, they [in vitro and rodent models] cannot replace long term studies of function in animals including NHPs.” (p. 25). The section on the 'Use of NHPs in Xenotransplantation' provides no evidence to support the need for NHPs in xenotransplantation research, nor any evidence to indicate that xenotransplantation itself is likely to ever be clinically useful. Although several formidable obstacles to xenotransplantation exist, the greatest is the rejection of transplanted organs. A 2005 review concluded that no durable mechanism for the control of hyperacute rejection has emerged, despite enormous effort, that additional complexities relating to immune response will undoubtedly face researchers in the future and any progress will be slow at best, and that lack of host survival and potential for infection would preclude clinical trials for the foreseeable future (71). It is therefore disappointing that the WG was not more critical of the need for NHP-based xenotransplantation research.

\section{Discussion}

An investigation of such gravity, with serious consequences for human health as well as the welfare 
of NHPs, should not have been so fundamentally and seriously flawed as the SCHER inquiry. The remit given to the SCHER was scarcely addressed; the Working Group (WG) had a paucity of expertise in NHP research and alternative methods; and voluminous and crucial evidence illustrating the inefficacy of NHP research and indicative of the power of replacement methods was ignored, resulting in a severely biased report replete with unsubstantiated claims in favour of NHP use.

The SCHER presumed the validity and human relevance of NHP research; supporting evidence was scant, anecdotal and opinion-based, rather than comprehensive, systematic and scientific. The SCHER should have ascertained the validity, scientific performance and human relevance of the NHP models currently being used in research and testing; instead, it sought to find flaws in proposed alternatives. It is not acceptable for the WG to simply state that it considered all relevant evidence the onus was on the committee to show that it did so, and to demonstrate its impartiality by evaluating all relevant evidence in a rigorous manner and discussing it in the Opinion in a balanced manner.

Because the EU is basing its approach to NHP research directly on the inquiry's findings in the revision to the animal experiments directive, which is currently being considered by the European Parliament, the implications of a flawed analysis about the efficacy of NHP research are extremely serious, both for animal welfare and for human health and safety. The conduct of the SCHER inquiry, and its published Opinion, should therefore be of major and widespread concern and should not be given any political, scientific or legislative credibility.

\section{References}

1. European Commission (1986). Council Directive 86/609/EEC of 24 November 1986 on the approximation of laws, regulations and administrative provisions of the Member States regarding the protection of animals used for experimental and other scientific purposes. Official Journal of the European Union L358, 18.12.1986, 1-28. Available at: http://eur-lex.europa.eu/LexUriServ/LexUriServ. do?uri=CELEX:31986L0609:en:HTML (Accessed 24.08.09).

2. Anon. (2003). Public Says 'No' to Primate Research. [Animal Aid press release.] Tonbridge, Kent, UK: Animal Aid. Available at: https://secure.wsa.u-net. com/www.animalaid.org.uk/press/0306prim.htm (Accessed 24.08.09).

3. Aldhous, P., Coghlan, A. \& Copley, J. (1999). Animal experiments: Where do you draw the line? New Scientist, 22 May, No. 2187, 26-31.

4. ECEAE (2009). Opinion Poll on Animal Experiments Launched. London, UK: European Coalition to End Animal Experiments. Available at: http:// www.eceae.org/news.php?p=492\&more=1 (Accessed 24.08.09).

5. European Parliament (2007). Written Declaration
Pursuant to Rule 116 of the Rules of Procedure by Jens Holm, Rebecca Harms, John Bowis, Martine Roure and Mojca Drčar Murko on Primates in Scientific Experiments (0040/2007), 2pp. Brussels, Belgium: European Parliament. Available at: http:// ec.europa.eu/environment/chemicals/lab_animals/ pdf/declaration_nhp_en.pdf (Accessed 24.08.09).

6. SCHER (2009). The Need for Non-human Primates in Biomedical Research, Production and Testing of Products and Devices, 38pp. Brussels, Belgium: Scientific Committee on Health and Environmental Risks, European Commission, Health \& Consumer Protection DG. Available at: http://ec.europa.eu/ health/ph_risk/committees/04_scher/docs/scher_o_ 110.pdf (Accessed 24.08.09).

7. Barnes, K. (2008). New Data Adds Weight to Case for Microdosing. Montpellier, France: Decision News Media (outsourcing-pharma.com). Available at: http://www.outsourcing-pharma.com/PreclinicalResearch/New-data-adds-weight-to-case-formicrodosing (Accessed 24.08.09).

8. Garner, R.C. (2005). Less is more: the human microdosing concept. Drug Discovery Today 10, 449-451.

9. National Research Council (2007). Toxicity Testing in the 21st Century: A Vision and a Strategy, 4pp. Washington, DC, USA: National Academies Press. Available at: http://dels.nas.edu/dels/rpt_briefs/ Toxicity_Testing_final.pdf (Accessed 24.08.09).

10. Biopta (undated). Human Pharmacological Services: Cardiovascular Adverse Effect Screening in Man, 1p. Glasgow, UK: Biopta. Available at: http:// www.biopta.com/upload/file/main/C 5.\%20 Cardiovascular\%20Safety\%20Screening\%20in\%20 Human\%20Tissue.pdf (Accessed 24.08.09).

11. Khetani, S.R. \& Bhatia, S.N. (2008). Microscale culture of human liver cells for drug development. Nature Biotechnology 26, 120-126.

12. Hewitt, N.J., Bühring, K.U., Dasenbrock, J., Haunschild, J., Ladstetter, B. \& Utesch, D. (2001). Studies comparing in vivo:in vitro metabolism of three pharmaceutical compounds in rat, dog, monkey, and human using cryopreserved hepatocytes, microsomes, and collagen gel immobilized hepatocyte cultures. Drug Metabolism \& Disposition: The Biological Fate of Chemicals 29, 1042-1050.

13. Anon. (2009). Invitrogen AlgiMatrix ${ }^{\mathrm{TM}} 3 \mathrm{D}$ Cell Culture System. Carlsbad, CA, USA: Invitrogen Corporation. Available at: http://www.invitrogen. $\mathrm{com} / \mathrm{site} / \mathrm{us} / \mathrm{en} / \mathrm{home} /$ Products-and-Services/ Applications/Cell-Culture/3D-Cell-Culture/ 3D_Cell_ Culture-Misc/AlgiMatrix.html (Accessed 24.08.09).

14. Elkayam, T., Amitay-Shaprut, S., Dvir-Ginzberg, M., Harel, T. \& Cohen, S. (2006). Enhancing the drug metabolism activities of C3A - a human hepatocyte cell line - by tissue engineering within alginate scaffolds. Tissue Engineering 12, 13571368.

15. Toh, Y.C., Zhang, C., Zhang, J., Khong, Y.M., Chang, S., Samper, V.D., van Noort, D., Hutmacher, D.W. \& Yu, H. (2007). A novel 3D mammalian cell perfusionculture system in microfluidic channels. Lab on $a$ Chip 7, 302-309.

16. Kimura, H., Yamamoto, T., Sakai, H., Sakai, Y. \& Fujii, T. (2008). An integrated microfluidic system for long-term perfusion culture and on-line monitoring of intestinal tissue models. Lab on a Chip 8, 741-746.

17. Hung, P.J., Lee, P.J., Sabounchi, P., Lin, R. \& Lee, 
L.P. (2005). Continuous perfusion microfluidic cell culture array for high-throughput cell-based assays. Biotechnology \& Bioengineering 89, 1-8.

18. Hillier, C. \& Bunton, D. (2007). Functional human tissue assays. Drug Discovery Today 12, 382-388.

19. Reed, A. (2004). Biopta wins £575,000 drug-testing boost. The Scotsman, 20 November 2004. Available at: http://thescotsman.scotsman.com/business/ Biopta-wins-575000-drugtesting-boost.2581689.jp (Accessed 24.08.09).

20. Byers, A.M., Tapia, T.M., Sassano, E.R. \& Wittman, V. (2009). In vitro antibody response to tetanus in the MIMIC system is a representative measure of vaccine immunogenicity. Biologicals 37, 148-151.

21. Anon. (2009). MIMIC ${ }^{\mathbb{B}}$ technology: High-throughput Process. Orlando, FL, USA: VaxDesign Corporation. Available at: http://www.vaxdesign.com/ mimic-technology/overview/high-throughput-process? ref=promo (Accessed 24.08.09).

22. Gottwein, J.M. \& Bukh, J. (2008). Cutting the gordian knot-development and biological relevance of hepatitis C virus cell culture systems. Advances in Virus Research 71, 51-133.

23. Gershon, D. (2002). Malaria research tools up for the future. Nature, London 419, 4-5.

24. Sattabongkot, J., Yimamnuaychoke, N., Leelaudomlipi, S., Rasameesoraj, M., Jenwithisuk, R., Coleman, R.E., Udomsangpetch, R., Cui, L. \& Brewer, T.G. (2006). Establishment of a human hepatocyte line that supports in vitro development of the exo-erythrocytic stages of the malaria parasites Plasmodium falciparum and $P$. vivax. American Journal of Tropical Medicine \& Hygiene 74, 708-715.

25. Nguyen, T.V., Fujioka, H., Kang, A.S., Rogers, W.O., Fidock, D.A. \& James, A.A. (2001). Stagedependent localization of a novel gene product of the malaria parasite, Plasmodium falciparum. Journal of Biological Chemistry 276, 26,72426,731.

26. Peters, J., Fowler, E., Gatton, M., Chen, N., Saul, A. \& Cheng, Q. (2002). High diversity and rapid changeover of expressed var genes during the acute phase of Plasmodium falciparum infections in human volunteers. Proceedings of the National Academy of Sciences of the USA 99, 10,689-10,694.

27. Lu, Z., Douthitt, M.P., Taffs, R.E., Ran, Y., Norwood, L.P. \& Chumakov, K.M. (1993). Quantitative aspects of the mutant analysis by PCR and restriction enzyme cleavage (MAPREC). PCR Methods \& Applications 3, 176-180.

28. WHO Expert Committee on Biological Standardization (1999). 48th Report: World Health Organization Technical Report Series 889, i-vi, 1-111. Geneva, Switzerland: World Health Organization. Available at: http://whqlibdoc.who.int/trs/WHO_ TRS_889.pdf (Accessed 24.08.09).

29. Ascherio, A., Chen, H., Weisskopf, M.G., O’Reilly, E., McCullough, M.L., Calle, E.E., Schwarzschild, M.A. \& Thun, M.J. (2006). Pesticide exposure and risk for Parkinson's disease. Annals of Neurology 60, 197-203.

30. Brück, A., Portin, R., Lindell, A., Laihinen, A., Bergman, J., Haaparanta, M., Solin, O. \& Rinne, J.O. (2001). Positron emission tomography shows that impaired frontal lobe functioning in Parkinson's disease is related to dopaminergic hypofunction in the caudate nucleus. Neuroscience Letters $\mathbf{3 1 1}$, 81-84.
31. Sanai, N., Tramontin, A.D., Quinones-Hinojosa, A., Barbaro, N.M., Gupta, N., Kunwar, S., Lawton, M.T., McDermott, M.W., Parsa, A.T., ManuelGarcía Verdugo, J., Berger, M.S. \& Alvarez-Buylla, A. (2004). Unique astrocyte ribbon in adult human brain contains neural stem cells but lacks chain migration. Nature, London 427, 740-744.

32. Boscolo, E., Pavesi, G., Zampieri, P., Conconi, M.T., Calore, C., Scienza, R., Parnigotto, P.P. \& Folin, M. (2006). Endothelial cells from human cerebral aneurysm and arteriovenous malformation release ET-1 in response to vessel rupture. International Journal of Molecular Medicine 18, 813-819.

33. Jin, K., Wang, X., Xie, L., Mao, X.O., Zhu, W., Wang, Y., Shen, J., Mao, Y., Banwait, S. \& Greenberg, D.A. (2006). Evidence for stroke-induced neurogenesis in the human brain. Proceedings of the National Academy of Sciences of the USA 103, 13,198-13,202.

34. Noraberg, J., Poulsen, F.R., Blaabjerg, M., Kristensen, B.W., Bonde, C., Montero, M., Meyer, M., Gramsbergen, J.B. \& Zimmer, J. (2005). Organotypic hippocampal slice cultures for studies of brain damage, neuroprotection and neurorepair. Current Drug Targets. CNS \& Neurological Disorders 4, 435-452.

35. Gold, J.J., Smith, C.N., Bayley, P.J., Shrager, Y., Brewer, J.B., Stark, C.E., Hopkins, R.O. \& Squire, L.R. (2006). Item memory, source memory, and the medial temporal lobe: concordant findings from fMRI and memory-impaired patients. Proceedings of the National Academy of Sciences of the USA 103, 9351-9356.

36. Shrager, Y., Bayley, P.J., Bontempi, B., Hopkins, R.O. \& Squire, L.R. (2007). Spatial memory and the human hippocampus. Proceedings of the National Academy of Sciences of the USA 104, 2961-2966.

37. Murphy, P.J., Duncan, A.L., Glennie, A.J. \& Knox, P.C. (2001). The effect of scleral search coil lens wear on the eye. The British Journal of Ophthalmology 85, 332-335.

38. McAuley, J.H., Rothwell, J.C. \& Marsden, C.D. (1999). Human anticipatory eye movements may reflect rhythmic central nervous activity. Neuroscience 94, 339-350.

39. Quiroga, R.Q., Reddy, L., Kreiman, G., Koch, C. \& Fried, I. (2005). Invariant visual representation by single neurons in the human brain. Nature, London 435, 1102-1107.

40. Vannucci, M., Pezer, N., Helmstaedter, C., Schaller, K., Viggiano, M.P., Elger, C.E. \& Grunwald, T. (2008). Hippocampal response to visual objects is related to visual memory functioning. Neuroreport 19, 965-968.

41. Johnson, E.J. \& Goldstein, D. (2003). Medicine. Do defaults save lives? Science, New York 302, 1338-1339.

42. Anon. (2000). Alternatives to Xenotransplantation. Campaign for Responsible Transplantation (CRT). Available at: http://www.crt-online.org/solutions. html (Accessed 24.08.09)

43. Awuonda, M. (1996). Swedish organ-donation law takes effect. The Lancet 348, 54.

44. Nicholson, M.L. \& Bradley, J.A. (1999). Renal transplantation from living donors. British Medical Journal 318, 409-410.

45. Yeatman, M., Smith, J.A., Dunning, J.J., Large, S.R. \& Wallwork, J. (1995). Cardiac transplantation: a review. Cardiovascular Surgery 3, 1-14.

46. Oster, G. \& Thompson, D. (1996). Estimated effects of reducing dietary saturated fat intake on the inci- 
dence and costs of coronary heart disease in the United States. Journal of the American Dietetic Association 96, 127-131.

47. Robinson, S., Delongeas, J.L., Donald, E., Dreher, D., Festag, M., Kervyn, S., Lampo, A., Nahas, K., Nogues, V., Ockert, D., Quinn, K., Old, S., Pickersgill, N., Somers, K., Stark, C., Stei, P., Waterson, L. \& Chapman, K. (2008). A European pharmaceutical company initiative challenging the regulatory requirement for acute toxicity studies in pharmaceutical drug development. Regulatory Toxicology \& Pharmacology: RTP 50, 345-352.

48. ICH (1993). ICH Harmonised Tripartite Guideline: Detection of Toxicity to Reproduction for Medicinal Products and Toxicity to Male Fertility, S5(R2), 24pp. (1993). Geneva Switzerland: International Conference on Harmonisation of Technical Requirements for Registration of Pharmaceuticals for Human Use. Available at: http://www.ich.org/ LOB/media/MEDIA498.pdf (Accessed 24.08.09).

49. Bailey, J. (2008). Developmental toxicity testing: protecting future generations? ATLA 36, 718-721.

50. Matthews, R.A. (2008). Medical progress depends on animal models - doesn't it? Journal of the Royal Society of Medicine 101, 95-98.

51. Spanhaak, S., Cook, D., Barnes, J. \& Reynolds, J. (2008). Species Concordance for Liver Injury: From the Safety Intelligence Program Board, 6pp. Cambridge, UK: BioWisdom, Ltd. Available at: http://www.biowisdom.com/files/SIP_Board_Species Concordance.pdf (Accessed 24.08.09).

52. da Silva, L.J. \& Richtmann, R. (2006). Vaccines under development: group B streptococcus, herpeszoster, HIV, malaria and dengue. Jornal de Pediatria 82, S115-24.

53. Tonks, A. (2007). Quest for the AIDS vaccine. British Medical Journal 334, 1346-1348.

54. D'Souza, M.P., Allen, M., Sheets, R. \& Johnston, M.I. (2004). Current advances in HIV vaccines. Current HIV/AIDS Reports 1, 18-24.

55. Johnston, M.I. (2000). The role of nonhuman primate models in AIDS vaccine development. Molecular Medicine Today 6, 267-270.

56. Taylor, K. (2006). Still Dying of Ignorance? 25 Years of Failed Primate AIDS Research. A Report by the $B U A V, 16 \mathrm{pp}$. London, UK: British Union for the Abolition of Vivsection. Available at: http://www. buav.org/media/files/References/BUAV_ReportAIDs.pdf (Accessed 24.08.09).

57. Hu, S.L. (2005). Non-human primate models for AIDS vaccine research. Current Drug Targets. Infectious Disorders 5, 193-201.
58. Levy, Y. (2005). Therapeutic HIV vaccines: an update. Current HIV/AIDS Reports 2, 5-9.

59. Tonini, T., Barnett, S., Donnelly, J. \& Rappuoli, R. (2005). Current approaches to developing a preventative HIV vaccine. Current Opinion in Investigational Drugs 6, 155-162.

60. Bailey, J. (2008). An assessment of the role of chimpanzees in AIDS vaccine research. ATLA $\mathbf{3 6}$, 381-428.

61. Bailey, J. (2005). Non-human primates in medical research and drug development: a critical review. Biogenic Amines 19, 235-256.

62. Duverlie, G. \& Wychowski, C. (2007). Cell culture systems for the hepatitis C virus. World Journal of Gastroenterology: WJG 13, 2442-2445.

63. Martin, M.J., Rayner, J.C., Gagneux, P., Barnwell, J.W. \& Varki, A. (2005). Evolution of humanchimpanzee differences in malaria susceptibility: relationship to human genetic loss of $\mathrm{N}$-glycolylneuraminic acid. Proceedings of the National Academy of Sciences of the USA 102, 12,819 12,824 .

64. Heppner, D.G., Cummings, J.F., Ockenhouse, C., Kester, K.E., Lyon, J.A. \& Gordon, D.M. (2001). New World monkey efficacy trials for malaria vaccine development: critical path or detour? Trends in Parasitology 17, 419-425.

65. Akhtar, A.Z., Pippin, J.J. \& Sandusky, C.B. (2008). Animal models in spinal cord injury: a review. Reviews in the Neurosciences 19, 47-60.

66. Huang, J., Mocco, J., Choudhri, T.F., Poisik, A., Popilskis, S.J., Emerson, R., DelaPaz, R.L., Khandji, A.G., Pinsky, D.J. \& Connolly, E.S., Jr (2000). A modified transorbital baboon model of reperfused stroke. Stroke 31, 3054-3063.

67. O'Collins, V.E., Macleod, M.R., Donnan, G.A., Horky, L.L., van der Worp, B.H. \& Howells, D.W. (2006). 1,026 experimental treatments in acute stroke. Annals of Neurology 59, 467-477.

68. Anon. (2006). Neuroprotection: the end of an era? The Lancet 368, 1548.

69. Emerich, D.F., Dean, R.L. \& Sanberg, P.R. (eds) (2000). Central Nervous System Diseases: Innovative Animal Models from Lab to Clinic, 532pp. New York, NY, USA: Humana Press.

70. Nelson, E.E. \& Winslow, J.T. (2009). Non-human primates: model animals for developmental psychopathology. Neuropsychopharmacology 34, 90-105.

71. Bailey, L.L. (2005). Candid observations on the current status of xenotransplantation. Xenotransplantation 12, 428-431. 